\title{
6
}

\section{ESCRITA E VISUALIDADE EM POESIA ÚLTIMA DE AMOR E ENFERMIDADE DE LOIS PEREIRO}

\section{WRITING AND VISUALITY IN LOIS PEREIRO'S POESIA ÚLTIMA DE AMOR E ENFERMIDADE}

\author{
Marcelo Cordeiro de Mello ${ }^{1}$ \\ Universidade Federal de Minas Gerais
}

Resumo: A proposta deste artigo é discutir a relação entre escrita e visualidade no livro Poesia última de amor e enfermidade do poeta galego Lois Pereiro, especialmente em quatro poemas, cujas traduções para o português são apresentadas como anexo. Transitamos entre autores que pensaram o problema do objeto-livro e da iconicidade da escrita, tais como: Roland Barthes, Michel Butor, Anne-Marie Christin, Georges Didi-Huberman, Gotthold Lessing, Stephane Mallarmé, Michel Melot, Georges Perec e Denis Roche. Por meio do pensamento destes autores, discutimos o problema da organização deste livro de Lois Pereiro, a partir do problema da página dupla e do diálogo intertextual que ela estabelece.

Palavras-chave: Lois Pereiro; Poesia galega; Escrita; Visualidade; Iconicidade da escrita.

\footnotetext{
${ }^{1}$ marcelocmello@gmail.com
} 
Abstract: This article proposes a discussion about the relationship between writing and visuality in the book Poesia última de amor e enfermidade by galician poet Lois Pereiro, specially four of its poems, for which portuguese translation are presented as an addendum. We move accross authors who have reflected upon the problem of the object-book and the iconicity of writing, such as: Roland Barthes, Michel Butor, Anne-Marie Christin, Georges Didi-Huberman, Gotthold Lessing, Stephane Mallarmé, Michel Melot, Georges Perec and Denis Roche. Through the ideas of these authors, we discuss the problem of the organization of Pereiro's book, from the problem of the double page and the intertextual dialogue that it establishes.

Keywords: Lois Pereiro; Galician poetry; Writing; Visuality; Iconicity of writing.

\section{SOBRE O AUTOR}

O poeta Lois Pereiro nasceu na região espanhola da Galícia e viveu entre 1958 e 1996. A língua galega, usada por Pereiro, tem grande proximidade com o português, o que desperta um interesse recíproco pelos falantes de ambas línguas. Entretanto, até hoje os poemas de Pereiro não foram editados em língua portuguesa. Por isso é apresentada aqui em anexo a tradução de quatro poemas de seu último livro, intitulado Poesia última de amor e enfermidade, sobre o qual trata o presente texto. Os poemas são: “Revisando os danos", os poemas XIII e XV da série "Luz e sombras de amor ressuscitado" e o poema que encerra o livro, "Poderia escolhê-lo como epitáfio".

Pertencente a uma geração de escritores que deve tanto ao expressionismo quanto à contracultura, Pereiro cunhou um estilo literário próprio e uma maneira própria de organizar seus textos poéticos.

Se seu primeiro livro, Poemas 1986/1991, segue a estrutura básica da recolha de textos do poeta que estreia em livro, há um procedimento muito mais radical na obra que será tratada aqui. Poesia última de amor e enfermidade é um livro-testamento escrito por um autor que sabia que ia morrer.

Nos anos noventa, a imprensa espanhola noticiou a intoxicação alimentar em massa causada por uma carga de óleo de canola envenenado. O episódio ficou conhecido na Espanha como "la enfermedad de la colza", ou seja, a "enfermidade da canola". Vítima desta intoxicação, Lois Pereiro viu-a abreviar 
severamente suas esperanças de vida, ao mesmo tempo em que sua imunidade se debilitava em decorrência da AIDS.

Ocorre então uma curiosa inversão na visão de mundo de um poeta acostumado a cantar a morte e o suicídio, e que dizia num de seus primeiros poemas, "Conspiração contra Lois":

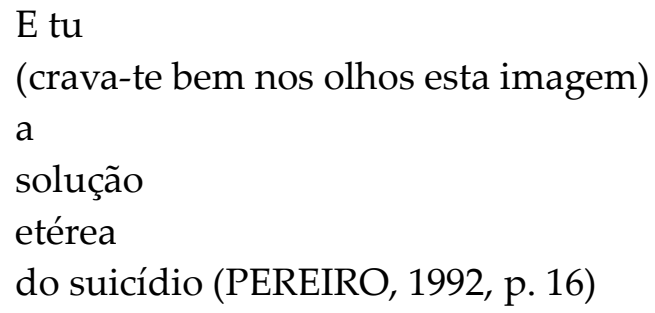

A postura diante da morte muda radicalmente em seu último livro: é sua "poesia última" porque o autor sabe que sua existência será limitada pela "enfermidade". Do desespero diante de uma morte iminente, nasce uma poesia de (re)descoberta da beleza, do erotismo, do amor e da vida.

Escrito ao longo do ano de 1995, todos os poemas trazem algum tipo de datação, que permite acompanhar a evolução de sua poesia de acordo com a aproximação da morte. Pereiro teve tempo de ver seu livro lançado, morrendo poucos meses depois.

\section{POESIA ÚLTIMA DE AMOR E ENFERMIDADE}

Em Poesia última de amor e enfermidade, Lois Pereiro reelabora alguns procedimentos da sua poética. O aspecto estrutural mais importante neste livro é o uso da dupla página. Enquanto à direita são apresentados os poemas, a página da esquerda funciona como uma espécie de preâmbulo ao poema. Ela contém quase sempre citações, que funcionam como epígrafe, bem como considerações do próprio poeta (ou do eu-lírico?) a respeito da composição de cada poema. 
A página da esquerda apresenta um texto estilisticamente híbrido, em que sobressaem elementos poéticos, em especial a quebra de linha, que parece ser determinada pelo ritmo. O poeta também faz uso da pontuação para dividir o texto em espaços, nos quais, geralmente, as epígrafes vêm entre aspas, e as considerações do autor/eu-lírico vêm entre parênteses.

Assim, o livro estabelece uma estrutura em que cada poema dialoga com um micro-texto (poético) que trata de sua composição, no qual se encontra(m) também a(s) epígrafe(s).

A divisão entre as páginas esquerda e direita também explora o espaço de cima e de baixo: ao longo de todo o livro, o texto está recuado para baixo na página da esquerda, enquanto que na página da direita, o poema começa na parte de cima. O livro tem o formato do quiasma.

\section{EPÍGRAFE E FRAGMENTO}

O uso de epígrafes (notadamente de poesia) sempre foi recorrente na obra de Pereiro, que pretendia estabelecer um diálogo com os autores de que gostava.

Nos quatro poemas escolhidos aqui para análise, há referências a: Paul Valéry, Paul Celan, Guillaume Apollinaire e T. S. Elliot. Observe-se o fato de que estes são quatro poetas que se dedicaram também à crítica, à tradução e à teorização do fazer poético e artístico.

Quase sempre, a epígrafe escolhida por Pereiro consiste num único verso, ou em poucos versos. Este "recorte" que o autor estabelece das obras alheias permite pensar o problema do fragmento. É curioso observar que Roland Barthes procurou associar fragmento e verso poético. Para ele, o fragmento

implica um gozo imediato: é um fantasma de discurso, uma abertura de 
desejo. Sob a forma de pensamento-frase, o germe do fragmento nos vem em qualquer lugar: no café, no trem, falando com um amigo (surge naturalmente daquilo que ele diz ou daquilo que digo); a gente tira então o caderninho de apontamentos, não para anotar um "pensamento", mas algo como o cunho, o que se chamaria outrora um "verso". (BARTHES, 2005, p. 102)

Em A preparação do Romance, Barthes retoma uma distinção esboçada por Mallarmé entre dois tipos de obra literária: o livro e o álbum. A oposição entre os dois se dá basicamente pela preocupação com a estrutura (BARTHES, 2005, p. 123), que é evidente no livro; já no álbum, a estrutura é arbitrária.

No livro de Lois Pereiro aqui abordado, o uso das epígrafes poéticas cria um texto aparentemente fragmentário, como um mosaico em que cacos se unem para formar um todo coerente. Entretanto, fica muito claro o cuidado que Pereiro teve na organização e elaboração da estrutura de Poesia última de amor e enfermidade, que claramente o aproxima da concepção de "livro" de Barthes e Mallarmé. O caráter fragmentário não diminui em nada a impressão de uma obra minuciosamente pensada.

\section{LÍNGUAS ESTRANGEIRAS}

Ainda no que diz respeito às epígrafes, cabe aqui uma observação particular sobre a questão do uso de línguas estrangeiras. A mais importante delas é certamente o castelhano. Para um escritor galego, escrever em língua galega é um ato de resistência. Tendo nascido e morado numa grande capital como A Corunha, Lois Pereiro viveu imerso em ambientes onde predomina a língua castelhana. Isto fica evidente também nas inúmeras referências que faz a poetas de língua castelhana (Valente, Fonollosa, Jímenez, entre outros).

Tendo vivido na Alemanha, Pereiro também se alimenta muito da tradição poética germânica, que cita abundantemente.

A língua portuguesa não poderia estar ausente, afinal, há uma 
identificação crescente dos escritores galegos com o português, chegando-se a um ponto em que "muitos escritores galegos contemporâneos optam por escrever diretamente em português" (VARGAS, 2009, p. 16). Este não é o caso de Pereiro, entretanto, há um detalhe curioso: numa citação de Camões na página esquerda, há um erro de ortografia na palavra "todo" (grafada como "tudo"); o erro só parece reafirmar o sentido do verso camoniano, assim grafado: "Errei tudo o discurso dos meus anos" 2 .

O uso de língua estrangeira não se limita à página esquerda, já que há um poema visual escrito parcialmente em língua francesa (o número XV da série "Luz e sombras do amor ressuscitado"). Neste poema, há inúmeros erros em relação à ortografia francesa, que são aqui mantidos, tendo a tradução se limitado a transpor para língua portuguesa os trechos em língua galega.

\section{A PÁGINA}

Michel Melot enxerga como componente estrutural do livro o que chama de "dobra": trata-se da dobra da própria folha, fechada em livro, que faz surgir uma "terceira dimensão", espinha dorsal do livro: "a dobra enriquece a superfície por ela atingida ao organizá-la em partes iguais, que permanecerão ligadas umas às outras"' (MELOT, 2012, p. 51).

O livro Espèces d'Espaces de Georges Perec abre com um capítulo intitulado "A página" ("La page"). Nele, Perec brinca com os limites comumente estabelecidos no mundo editorial para a página, criando um jogo na passagem de uma página à outra e procurando explorar os diferentes espaços da página. O autor realiza uma écfrase do próprio ato de escrever, que para ele é como "habitar a folha de papel". O uso da técnica de "mise en abyme" é recorrente neste escrito de Perec. O rodapé da página bem como a margem são utilizados

\footnotetext{
2 Verso do soneto Erros meus, má Fortuna, Amor ardente.
} 
de forma irônica, problematizando a sua função.

Que dizer então do recurso da dupla página, explorado por Lois Pereiro em Poesia última de amor e enfermidade?

Pereiro não foi o primeiro a utilizar a dupla página como componente estrutural de sua obra. Já Mallarmé, no prefácio ao Coup de dés, sublinhava a importância ali da "visão simultânea da página" (MALLARMÉ, 1980, p. 151). Como observa também Paul Valéry, o Coup de dés não é um poema composto em duas etapas,

uma que consiste em escrever o poema de maneira ordinária, isto é, independentemente de toda figura e das grandezas espaciais: outra que daria ao texto definitivamente parado a disposição conveniente 3 . (VALÉRY, 1957, p. 628)

Ou seja, a organização do espaço e a tipografia não podem ser vistos como elementos independentes, que teriam sido de alguma forma adaptados ao texto depois de sua composição inicial.

Caso as traduções de Lois Pereiro aqui apresentadas venham a ser publicadas, e caso se opte por uma edição bilíngue, o editor encontrará o mesmo problema que carregam obras com as de Mallarmé e Apollinaire. Na célebre "tridução" do Coup de dés de Mallarmé feita por Décio Pignatari e pelos irmãos Campos, foi rejeitado o uso do cotejamento das páginas esquerda e direita, comum em edições bilíngues. Numa recente tradução ${ }^{4}$ dos Caligramas de Apollinaire, tradutor e editor chegaram a uma solução inusitada para o único poema visual que utiliza o procedimento da dupla página: o caligrama de um trem feito por Apollinaire ganhou na edição brasileira páginas maiores, que se desdobram para fora, como se abrem as portas de um armário ou de uma

\footnotetext{
3 "l'une consistant à écrire un poème à la manière ordinaire, c'est-à-dire indépendamment de toute figure et des grandeurs spatiales: l'autre qui donnerait à ce texte définitivement arrêté la disposition convenable". Tradução minha.

${ }^{4}$ Trata-se da edição do Ateliê Editorial, traduzida por Álvaro Faleiros.
} 
janela sanfonada.

O caráter estrutural do uso da dupla página no Coup de dés vale para a obra de Lois Pereiro que abordamos aqui: o livro é inseparável da maneira como foi organizado, do enquadramento das páginas. Tanto no caso de Mallarmé quanto no de Pereiro, a "mise en page" do livro é definida pelas estruturas de pensamento que ele pretende representar.

Como já foi observado, Pereiro faz um uso abundante dos parênteses na página da esquerda para incluir comentários sobre a composição dos poemas. É curioso observar que recurso semelhante aparece em autores de prosa do século $\mathrm{XX}$ que procuraram reproduzir o pensamento humano por meio do chamado "fluxo de consciência". Por exemplo James Joyce e Guimarães Rosa fazem um uso da pontuação (e em especial dos parênteses) que pode em certa medida ser aproximado do procedimento de Pereiro - a pontuação ajuda a "dar a ver" o pensamento. Joyce, Rosa e também Pereiro dialogam com uma tradição que vê na expressão literária e/ou poética uma espécie de linguagem universal, capaz de dar voz ao pensamento humano. O procedimento lembra a afirmação de Paul Valéry após a primeira leitura do Coup de dés de Mallarmé: "Pareceu-me ver a figura de um pensamento pela primeira vez colocada em nosso espaço" 5 (VALÉRY, 1957).

Ao explorar a visualidade das páginas do livro aberto, Pereiro permite uma pluralidade de permutações de sentidos, em que o significado é contaminado pelo entorno, no que a professora Anne-Marie Christin chamaria de "efeitos de vizinhança".

No livro Quand les images prennent position, Georges Didi-Huberman trata de duas obras de Bertolt Brecht que misturam imagem e texto. Didi-Huberman utiliza como alegoria o xadrez e o go chinês, jogos em que a função das peças

\footnotetext{
5 "Il me sembla de voir la figure d'une pensée, pour la première fois placée dans notre espace". Tradução minha.
} 
varia de acordo com seu posicionamento dentro do espaço do tabuleiro. É na colocação (ou na montagem) destas peças que se instaura um jogo dialético e alegórico. Nesta obra, Didi-Huberman retoma seus próprios escritos a respeito do Atlas Mnemosine de Aby Warburg, no qual o confronto entre diferentes imagens permite a identificação de aspectos até então irreconhecíveis. Por meio desta composição (que é também decomposição, já que toda montagem é uma desmontagem de uma forma anterior), são revelados motivos, sintomas e relações transversais (o que permite a emergência de "sobrevivências" de formas imagéticas).

Estas noções de Christin e Didi-Huberman podem ser aproximadas também dos escritos teóricos do cineasta Eisenstein (cujo conceito de montagem, aliás, é abordado Didi-Huberman em Atlas ou a Gaia Ciência Inquieta).

Em O sentido do filme, Eisenstein descreveu como a montagem estrutura, ordena e dá sentido à narrativa fílmica. Ao falar da montagem, Eisenstein tratou deste encontro de sentidos (de que falam também Christin e Didi-Huberman), defendendo a maior proximidade analógica com a multiplicação do que com a adição de sentidos: "A justaposição de dois planos isolados através de sua união não parece a simples soma de um plano mais outro plano - mas o produto" (EISENSTEIN, 1990, p. 16).

Neste ponto pode-se recordar também a obra fotográfica e a teorização do escritor e fotógrafo Denis Roche: seu conceito de fotolalia procura extrair um sentido (a própria noção de estilo) do encontro entre duas imagens fotográficas. $\mathrm{O}$ cotejamento destas imagens, semelhantes embora diferentes, suscita a invenção de uma narrativa que "explique" a transição de uma foto para a outra - num procedimento bastante semelhante ao da montagem cinematográfica descrita por Eisenstein.

A contaminação de sentidos proposta por Pereiro envolve apenas dois 
elementos: na estrutura em dístico, um lado da página dialoga com o outro; há, portanto, semelhança com as duplas de fotografias, as fotolalias de Denis Roche.

Um exemplo comparável é do livro Cent Mille Milliards de Poèmes de Raymond Queneau, no qual a permutação de versos vai criando novos sentidos. Porém, enquanto Pereiro e Denis Roche chamam a atenção para um confronto de apenas dois sentidos, Queneau multiplica os sentidos para muito além da própria capacidade do leitor, que jamais será capaz de realizar o número total de combinações.

\section{DIREITA E ESQUERDA}

O formato do livro em que a página da esquerda é vista ao mesmo tempo que a página da direita foi problematizado por inúmeros escritores a partir da passagem do século XIX ao XX.

Como já foi dito, Lois Pereiro utiliza a página esquerda como uma espécie de "prefácio" ao poema que aparece na página direita. Está colocado aí claramente um pressuposto da ordem de leitura. A etimologia da palavra "prefácio" significa "ação de falar ao princípio de" (segundo o dicionário Houaiss de 2002). Por outro lado, o fato de a numeração do índice fazer

referência sempre à página da direita (e ao título do poema) pressupõe a primazia da página direita - elemento característico do livro ocidental, e com o qual Perec brinca no já citado capítulo "A página".

O problema da ordenação é bastante característico da literatura do século XX. Haroldo de Campos cogitou publicar o seu Galáxias no formato de uma caixa contendo páginas soltas, de ordem intercambiável. Fernando Pessoa deixou inacabado o seu Livro do Desassossego, o que levou um dos editores da obra a afirmar que "é mesmo possível pensar-se numa edição em páginas 
soltas, como cartas de baralho, que possam ser lidas em infinitos arranjos" (BLANCO, 2008, p. 417). O projeto não-realizado do "Livro" de Mallarmé também procurava fugir à ordenação, ao propor um formato redondo, sem começo nem fim, numa disposição não-linear.

Porém, no tradicional livro sanfonado ocidental (como é o caso da obra de Pereiro aqui tratada), há uma simultaneidade de elementos que se deve à abertura concomitante das páginas esquerda e direita.

Dentro dos estudos interartísticos, Lessing inovou ao propor uma comparação seminal entre os diferentes meios e suportes artísticos. Uma das diferenças fundamentais que Lessing vê entre a Poesia e a Pintura é que, na primeira, há simultaneidade do tempo, e, na segunda, justaposição do espaço (MOSER, 2006, p. 45). Ou seja: enquanto na poesia há uma sequência das partes, na pintura, tudo é apresentado em conjunto.

Entretanto, fica difícil tomar as noções de Lessing para abordar as obras artísticas mais recentes. O que Pereiro parece propor em sua obra é a união entre as camadas do espaço e do tempo, compondo uma única simultaneidade. O fato de explorar a noção de iconicidade da letra, por meio da poesia visual, complexifica a questão, já que o poema visual é uma obra artística híbrida.

A oposição feita por Lessing entre "artes do espaço" (pintura e escultura) e "artes do tempo" (poesia e ficção) é problemática porque, como argumenta Christin, "uma imagem, para ser 'vista', sempre demanda que seja percorrida mais ou menos longamente pelo olhar" (CHRISTIN, 2006, p. 66). Na obra de Pereiro, como foi dito, o uso da dupla página instaura uma relação em que o olhar oscila entre uma página e outra; logo, o sentido de uma página passa a ser dependente do da outra.

Para o leitor contemporâneo, cada vez mais a noção de livro se afasta das duas páginas abertas. Uma leitura feita em um tablet ou num leitor de livros digitais (de tipo kindle) provavelmente passará por cada página isoladamente, 
ou ainda, por cada pedaço do texto, fazendo oscilar pouco a pouco a barra de rolagem. Assim, a contaminação recíproca de sentidos só pode ser feita a partir da memória do leitor. Procedimento bastante semelhante acontece no cinema, em que a montagem depende da memória do espectador para recompor em forma de narrativa os fatos vistos e ouvidos. Por isso Eisenstein compara o cinema à pintura de rolo chinesa, em que a imagem (enrolada em pergaminho por ser longa demais) só pode ser contemplada um pedaço de cada vez.

\section{LIVRO E CORPO}

O poema "Revisando os danos" começa evocando a separação entre os lados direito e esquerdo, o que sugere uma relação entre o livro e o corpo humano. A simetria do corpo humano é aqui comparada à do livro. A reafirmação da imagem poética da mão remete à concepção barthesiana da obra como “o que se segura na mão" (BARTHES, 2005).

Poesia última de amor e enfermidade - livro do qual quatro poemas formam o corpus deste artigo - é um corpo inviolável: separar suas metades é desfazer para sempre a sua unidade e desfazer também a própria noção de corpo único. Isto porque o corpo "não tem metade", como afirma Jean-Luc Nancy, em 58 indícios sobre o corpo: "Ou senão a metade é um picadinho, uma anatomia, um esboço, e nada disso dá em corpo".

Em "Revisando os danos", há uma reafirmação do óbvio: as partes do corpo estão do lado em que deveriam estar. A datação do poema deixa pressupor que a saúde do escritor começava a se deteriorar. Durante a celebração do Natal (quando são reencontrados entes próximos que não foram vistos ao longo do ano) a passagem do tempo pode ser reconhecida nos corpos. Os "danos" ao corpo de Pereiro são assim "revisados". Logo, o poema pode ser entendido como uma última constatação da integridade do corpo antes do 
começo da decadência que o levará à morte (menos de dois anos depois de escrito este poema).

A distinção entre esquerda e direita também evoca uma preocupação constante da poesia de Pereiro: a questão política. O autor inicia um livro de prosa engajada da juventude com o questionamento: "De que lado estou eu?"6. Sua defesa de uma ideologia de extrema-esquerda parece se adequar à figura que Pereiro adquiriu: a do escritor marginal e desajustado que sofre, porém vive apaixonadamente. Como Drummond, também Pereiro foi "gauche na vida".

\section{TÍTULOS}

A alegoria das duas portas divide o livro em duas metades: dois lados da moeda, dois princípios opostos, como sol e lua, masculino e feminino. O duplo remete também a um problema fundamental da poesia: a rima.

Um dos poemas mais claramente metalinguísticos de Pereiro, “Triangulações”, traz na página da esquerda versos de Paul Celan (cujo nome, simbolicamente, aparece em negrito, usado raramente no livro). Estabelece-se uma relação entre as "as duas portas do mundo", de que fala o poema de Celan, e as duas páginas do livro de Pereiro, relação na qual a obra poética permite a "abertura" de portas e a "entrada" alegórica no mundo.

Seria interessante recordar aqui o projeto artístico do poeta chileno Ivan Zurita, que em 1982 reuniu cinco aviões que traçaram com fumaça nos céus de Nova Iorque os versos de seu poema "La Vida Nueva”.

O poema de Pereiro evoca um céu dividido em duas metades. Pode-se pensar numa oposição entre elevação e baixeza de espírito. A divisão do céu não tem ponto de referência: esquerda e direita ou cima e baixo. Estas noções

\footnotetext{
6 Trata-se da Modesta proposição para renunciar a fazer girar a roda hidráulica de uma cíclica história universal da infâmia.
} 
encontram-se traduzidas também na organização das páginas do livro de Pereiro e no seu formato em quiasma.

Mallarmé procurou estabelecer no Coup de dés uma lógica em que a colocação em cima ou embaixo alterava a entonação da leitura daquele verso ou palavra - de forma semelhante à partitura musical.

Embora não vá neste sentido, Pereiro explora a verticalidade da página, valorizando os espaços vazios, que podem ser entendidos como espaços de abertura do mundo. Este jogo de disposição da escrita lembra o que Christin afirma sobre a importância do vazio na representação de paisagens da pintura chinesa, e de sua relação com a caligrafia: "a experiência fundadora não é a do traço, mas a do 'vazio'" (CHRISTIN, 2006, p. 76).

Pereiro trabalha de maneira contrastiva a disposição vertical da página. Assim, o verso de Paul Valéry toma conotação irônica na página à esquerda de "Revisando os danos": "o vento se levanta", afirma o verso (num trocadilho com a imagem poética do sol nascente e com a frase "o sol se levanta"). Porém, o verbo "levantar" aparece justamente na parte mais baixa da página, o que lhe confere uma disposição visual que entra em choque com seu sentido. A oposição entre vida e morte reforça este campo alegórico, em que o baixo pode representar a corporalidade humana, e o alto, a ascensão aos céus. Contraste semelhante está em "Triangulações", onde a página esquerda usa a expressão "alta noite", retirada do poema de Celan. Entretanto, a expressão aparece justamente na parte mais baixa da página. Estes "efeitos de diferença" provocados por Pereiro podem ser relacionados à noção de "ilustração transgressiva" de Christin?.

\footnotetext{
7 Apresentada na conferência $D a$ ilustração como transgressão (De l'illustration comme transgression), realizada na Faculdade de Letras da Universidade Federal de Minas Gerais em $18 / 8 / 2009$.
} 


\section{LETRAS E CORPOS}

A poesia de Pereiro se preocupa com a questão da iconicidade da escrita. A própria representação das letras do alfabeto é problematizada no longo poema "ABC Galícia" Por exemplo, a letra jota, inexistente no galego, e profundamente associada ao castelhano, é descrita assim: "Som oriental. Rotundidade do sul" (PEREIRO, 1992, p. 92). A Galícia fica no norte da Espanha.

Embora a maioria dos poemas de Poesia última de amor e enfermidade tenham títulos, em alguns casos o título é dado apenas a um conjunto de poemas, que é numerado. A escolha da numeração romana parece significativa, por manter os signos dentro do código alfabético.

Assim, seria possível encontrar nos números romanos dos títulos de alguns poemas de Pereiro algumas sugestões icônicas. Na série “Luz e sombras de amor ressuscitado", o poema "Triangulações" recebe o número XIII: o "X" pode ter aparência antropomórfica, sendo acompanhado do número três, de importância central no poema.

A imagem triangular reaparece no poema visual do útero, estilização feita a partir de formas geométricas básicas (triângulo e losango). Coincidência ou não, este é o poema de número $\mathrm{XV}$, numeral romano em cujas letras encontramos os ângulos agudos que aparecem na representação visual do útero em losango. A própria letra " $\mathrm{v}$ " remete também ao vocabulário da anatomia feminina: "vagina", "vulva". Poderíamos repetir o que Barthes diz a respeito dos rebus: “a letra está na figura” (BARTHES, 1990, p. 96).

O tipógrafo Robert Massin recolheu um conjunto de alfabetos que transcendem a mera função da linguagem como "códice", explorando a visualidade de cada letra. Barthes observou que nestes alfabetos há uma

\footnotetext{
8 O poema está no primeiro livro de Pereiro, Poemas 1981/1991.
} 
"metamorfose figurativa": a articulação entre letra e palavra toma um "outro caminho, que é o caminho não da linguagem, mas da escrita, não da comunicação mas da significância" (BARTHES, 1990, p. 94).

Christin considera que a escrita nasceu da imagem. Assim, os alfabetos de Massin não fariam mais do que restaurar essa referencialidade perdida - que a escrita de Pereiro, por sua vez, reconstituiria poeticamente.

É curioso notar nos alfabetos de Massin uma metaforização constante das formas das letras com o corpo humano. Isto remete à maneira como Pereiro põe em paralelo a escrita e o corpo em "Revisando os danos", além de lembrar a possível significação por trás da visualidade dos números romanos na série "Luz e sombras de amor ressuscitado".

\section{TRIANGULAÇÕES}

O poema "Triangulações" traz uma sugestão erótica, em que o amor do casal passa a incluir um terceiro ente: "entramos na tua vida". A alusão sexual fica evidente na repetição: “bater bater bater”, que aparece na página esquerda. Quem seria este "tu", este terceiro a que se dirige o poema? O leitor? Ou talvez o poeta Paul Celan, com quem o poema dialoga?

O eu-lírico alude ao "teu útero amável sempre aberto", instaurando um diálogo com outro poema do mesmo livro. É o poema visual que tem o número "XV" na série "Luz e sombras de amor ressuscitado". Trata-se, como foi dito, de uma estilização da representação do útero, semelhante à que é encontrada em manuais escolares, com o posicionamento simétrico dos ovários. Numa simplificação de formas, Pereiro transforma o útero num losango, com a base triangular maior.

O triângulo é associado ao princípio feminino em inúmeras culturas, desde representações pré-históricas (como as Vênus paleolíticas) passando pelo 
mundo greco-romano e até pelas culturas ameríndias (veja-se na cerâmica ameríndia a representação do triângulo como símbolo de fertilidade, significando tanto o princípio feminino quanto aludindo ao formato de cereais, como o milho).

Neste caligrama de Pereiro, a simetria é reforçada: durante o processo de edição, o texto precisou ser centralizado. Vê-se como a simetria do corpo humano se reflete na simetria do poema visual. Mais uma vez, página e corpo se espelham.

\section{1 ÚTERO}

Neste poema visual do útero, a referência (na página esquerda) ao jogo de tarô remete ao fato de a posição dos elementos influenciar na leitura do conjunto. Basta lembrar como em Quand les images prennent position, DidiHuberman associa o xadrez e o jogo chinês do go com o sentido que emerge a partir da disposição de elementos em dois livros de Brecht que combinam texto e imagem.

Embora talvez não possa ser classificado propriamente como um livroobjeto, Poesia última de amor e enfermidade tem a característica de "chamar a atenção para si mesmo" (BUTOR, 1974), para o seu próprio processo de composição - um dos traços que o escritor Michel Butor associa ao livro-objeto.

Assim, na página ao lado esquerdo do caligrama de Pereiro, está a frase "fiz um poema em forma de útero", écfrase que pode funcionar como legenda do poema-imagem. Para além do plano metalinguístico, esta afirmação reforça a iconicidade da escrita. Como no ideograma oriental, o sentido é reforçado pela visualidade.

Do diálogo com Apollinaire surge o neologismo "apolligrama". A fusão entre criador e criatura parece reproduzir o problema da indissociabilidade 
entre a visualidade do caligrama e a função da linguagem como códice.

Símbolo de fertilidade, a imagem do útero reforça também a ideia do erotismo como fonte de vitalidade para o poeta diante da morte. Não é à toa que esta série de poemas, intitulada "Luz e sombras de amor ressuscitado", é dedicada a Piedad Cabo, companheira do escritor.

\section{VIDA E MORTE}

Butor entende que a obra inacabada de certa forma incita o crítico a "prolongar" a invenção do autor (BUTOR, 1974, p. 199). O que dizer então de Poesia última de amor e enfermidade? Obra escrita na iminência da morte e concluída antes da decadência total do corpo e da mente. O acabamento da obra se confunde com o fim da vida do escritor. Como deixa evidente o título, este é um livro que sabe ser o "último" do autor - o fim é determinado pela "enfermidade", e a salvação diante da morte é encontrada no "amor": tanto o amor erótico quanto o amor pela literatura, representada no diálogo com seus autores queridos, que neste livro têm um lugar especial (na página esquerda).

Pereiro optou por concluir seu livro-epitáfio com um poema que se apresenta apenas hipoteticamente como epitáfio, e não sem certa ironia. Aliás, a própria datação do poema (não com o nome do mês, mas com a estação "outono") confere ao poema certa luz crepuscular. Como já foi observado, a datação dos poemas os localiza no tempo, no percurso temporal em que o corpo do poeta - que de início se apresenta "em plenas faculdades" - vai se deslocando no caminho que o aproxima da morte.

As "Vanitas" são um topos da pintura europeia, em especial a holandesa. Este tipo de pintura funciona como uma "lista visual" (como entende Umberto Eco (2010)), em que elementos como a caveira (representação da morte) são exibidos em meio a outros objetos contrastantes, que retratam coisas vivas - 
com frequência, flores.

De forma análoga, em Poesia última de amor e enfermidade, a presença constante da morte é contrastada pela força do erotismo e pela presença das coisas vivas.

Este nosso artigo esteve dividido em doze partes - como a metade de um dia é dividida em doze horas, ou como o ano é dividido em doze meses. A dimensão da temporalidade responde à da espacialidade, problema de que trata este artigo, focado na poesia dos "últimos tempos" de Pereiro.

Circula na internet um vídeo em que, durante uma aula de Educação Física numa escola maternal da Corunha, um grupo de crianças de cinco anos recita o poema "Revisando os danos". O coro aos gritos é acompanhado de gestos que ilustram a dimensão corporal do poema. Ao final, o professor Kalim pergunta: “E como se chamava o poeta que fez esta poesia?" ao que as crianças respondem com entusiasmo: “Lois Pereiro!". Assim, o espaço da poesia vai prolongando o tempo de vida de Lois Pereiro... 
ANEXO

Páginas 20-21

Revisando os danos

A mão direita à direita do corpo

a mão esquerda à esquerda.

Em plenas faculdades

Tenho a cabeça no centro do mundo

e vou lhe trocando os argumentos

pelos meus sonhos escassos e prudentes.

Natal, 94

"Le vent se lève. Il faut tenter de vivre..."

Paul Valery 
Páginas 50-51

\begin{tabular}{|r|l|}
\hline & $\begin{array}{l}\text { XIII } \\
\text { (Triangulações) }\end{array}$ \\
O céu em duas metades transfundidas \\
no teu útero amável sempre aberto: \\
ela e mais eu em comunhão perfeita \\
entramos na tua vida \\
e a habitamos.
\end{tabular}


(Apollinaire?... apollinaire, apolligrama, caligraire Madame Sosostris botoume as cartas. E fiz um poema

em forma de útero.

Devo sonhar desperto em tudo o que há de erótico na terra. Ser amável, levemente perverso:

e aproveitar a gratuidade

XV

Soir. La femme qui est derrière moi me regarde á travers du miroir que j'aie dévant ma face. Soir. Et le soleil brule nos ames. Le désir chante. Et moi, maintenant, tout hereux d'être vivant.

Amo-te. Soir. Serão. A mulher que tenho detrás observame

pelo espelho há justo diante de mim. Serão. O sol está ardendo nas nossas almas. Canta o desejo. E eu, agora, feliz de continuar vivo. Je t'aime. Serão. Escrevo isto com calma e sigo sendo o mesmo, ou isso penso.

Creio.

Julho, 95 
"Shall I at least set my lands in order? London Bridge is falling down falling down falling down (...)

These fragments I have shored against my ruins"

The Waste Land

T. S. Eliot

(E finalmente, com sono atrasado, mal vivido porém feliz, sério e satisfeito, já posso regressar ao meu cadáver)

Poderia escolhê-lo como epitáfio

Cuspam-me em cima quando passarem por diante do lugar em que eu repousar enviando-me uma úmida mensagem de vida e de fúria necessária.

Outono, 95 


\section{REFERÊNCIAS}

REVISANDO OS DANOS. Disponível em: [https://vimeo.com/23489631]. Acesso em: $25 / 02 / 2021$.

BARTHES, Roland. “O espírito da letra”. In: BARTHES, Roland. O óbvio e o obtuso, Rio de Janeiro: Nova Fronteira, 1990. pp. 93-96.

BARTHES, Roland. A preparação do romance. São Paulo: Martins Fontes, 2005.

BLANCO, José. Livro do desassossego - História da Edição. In: MARTINS, Fernando Cabral. Dicionário de Fernando Pessoa e do Modernismo Português. Lisboa: Caminho, 2008. p. 417.

BUTOR, Michel. Repertório. São Paulo: Perspectiva, 1974.

CHRISTIN, Anne- Marie. A imagem enformada pela escrita. In: ARBEX, Márcia (org.). Poéticas do visível. Ensaios sobre a escrita e a imagem. Belo Horizonte: Programa de PósGraduação em Letras: Estudos Literários - Faculdade de Letras - UFMG, 2006. pp. 63105.

DIDI-HUBERMAN, Georges. Quand les images prennent position. L'oeil de l'histoire, 1. Paris: Minuit, 2009.

ECO, Umberto. A vertigem das listas. Rio de Janeiro: Record, 2010.

EISENSTEIN. A forma do filme. Rio de Janeiro: Jorge Zahar, 1990.

MALLARMÉ, Stephane. Mallarmé. Organização e tradução de Augusto de Campos, Décio Pignatari e Haroldo de Campos. São Paulo: Perspectiva, 1980.

MELOT, Michel. Livro. Capítulo 2: “Assim pensa a dobra". Cotia: Ateliê, 2012.

MOSER, Walter. As relações entre as artes: por uma arqueologia da intermidialidade. Aletria, [S. l.], v. 14, n. 2, p. 42-65, 2006.

PEREC, Georges. La page. In: PEREC, Georges. Espèces d'espaces. Paris: Galilée. 1974.

PEREIRO, Lois. Poemas 1981/1991. Santiago de Compostela: Positivas, 1992.

PEREIRO. Poesía última de amor e enfermidade (1992-1995). Santiago de Compostela: Positivas, 1995. Primeira edição: dezembro de 1995. Segunda edição: janeiro de 2006.

PEREIRO. Poemas para unha loia. A Corunha: Espiral Maior, 1997.

ROCHE, Denis. La disparition des lucioles (réflexions sur l'acte photographique). [S. l.]: Éditions de l'Étoile, 1982.

VALÉRY, Paul. In: VALÉRY, Paul. Les Marges, 15 de fevereiro de 1920.

VALÉRY, Paul. CEuvres. Collection Bibliothèque de la Pléiade, Gallimard, 1957.

VARGAS, Fábio Aristimunho. Poesia Galega: das origens à guerra civil. São Paulo: Hedra, 2009.

Nota do editor:

Artigo submetido para avaliação em: 27 de fevereiro de 2021.

Aprovado em sistema duplo cego em: 22 de maio de 2021. 